\title{
Evaluation on the perception of final year dental students on their confidence level regarding endodontic treatments: a cross sectional analysis
}

Aws Hashim Ali Al Kadhim, Awathif Nor Azan², Muaz Muhammad Salim², Sarah Taha Yousif Al$\mathrm{Ani}^{3}$, Azlan Jaafar ${ }^{4}$

${ }^{1}$ Department of Conservative Dentistry and Prosthodontics, Faculty of Dentistry Universiti Sains Islam Malaysia (USIM), Kuala Lumpur, Malaysia

${ }^{2}$ Final Year Dental Student, Faculty of Dentistry, Universiti Sains Islam Malaysia (USIM), Kuala Lumpur, Malaysia

${ }^{3}$ Medical Officer, We Care clinic, Kuala Lumpur, Malaysia

${ }^{4}$ Department of Periodontology and Community Oral Health, Faculty of Dentistry Universiti Sains Islam Malaysia (USIM), Kuala Lumpur, Malaysia

\begin{abstract}
Endodontics procedures are difficult and complicated that most of the practitioners would encounter. Therefore, dental students should gain their confidence and competent during their training. This research aimed to study the perception of final year students on confidence level regarding endodontic treatments from all public universities and their opinions on the quality of endodontic education. A Google Form was used to disseminate an online questionnaire to all dental students from public universities across Malaysia. The survey included both scaled answer and open-ended questions. 184 responses out of 235 students, were obtained (response rate $=78 \%$ ). Perception of competence and confidence were significantly greater amongst the students from research-based universities group $(P<0.05) .93 .5 \% \quad(n=179)$ of participants agree that they were confident to do endodontic procedure on anterior tooth, whilst on posterior tooth, only $75.5 \%(n=139)$ were confident. Only 6.5 percent of participants $(n=12)$ did not feel confident doing root canal treatment on single-rooted teeth, but 76.1 percent $(n=$ 140) did not feel competent performing root canal treatment on multirooted teeth. Over $90 \%$ of the students rated the quality and the amount of time spent on endodontic education were adequate at their respective university as $\geq 5$ on a Likert scale $(1=$ inadequate to $10=$ adequate). In addition, when they were asked to give the suggestion on how to improve the quality of endodontic education, $10.9 \%$ of the students suggested to increase the number of practical session and to do regular discussion regarding endodontic cases. It is vital to improve undergraduate endodontic education in order to raise students' perceptions of their confidence and competence when doing root canal therapy.
\end{abstract}

Keywords: education, endodontics, root canal treatment, undergraduate dental students
Received:

24 October 2021

Revised:

2 December 2021

Accepted:

3 January 2022

Published Online:

4 March 2022

\section{How to cite this article:}

Ali Al-Kadhim, A. H., Nor Azan, A., Muhammad Salim, M., Yousif Al-Ani, S. T., \& Jaafar, A. Evaluation on the perception of final year dental students on their confidence level regarding endodontic treatments: a cross sectional analysis. IIUM Journal of Orofacial and Health Sciences, 3(1), 102-110. https://doi.org/10.31436/ijohs.

v3i1.114

Article DOI:

10.31436/ijohs.v3i1.114

*Corresponding author

Address:

Faculty of Dentistry, USIM

Level 15, Menara B,Persiaran MPAJ, Jalan Pandan Utama,

Pandan Indah, 55100

Kuala Lumpur, Malaysia

Telephone: +60342892430

Email address:

awshashim@usim.edu.my

\section{Introduction}

Endodontics is a specialist field of dentistry that focuses on the preservation of healthy periapical tissues as well as the healing of infected or inflammatory periapical tissues. Endodontic failures are on the rise, and their treatment necessitates a large number of clinical cases to be handled quickly in general dentistry (Gilmour et al., 2017). 
According to studies done in Sweden and United Kingdom, the number of people seeking endodontic treatment has risen dramatically during the last few decades (Skudutylte \& Eriksen, 2006, Brennan \& Spencer, 2003).

This could be linked to a growth in population life expectancy along with a growing desire to keep their natural teeth. Because of the increase in endodontic treatment needs, endodontics should be taught as a basic theoretical and clinical skill in the undergraduate dental curriculum. Future dental clinicians' knowledge and skills will be enhanced as a result. As a result, they will be able to provide safe endodontic treatment while also providing quality care to patients by performing accurate diagnosis, treatment planning, and skilled endodontic treatment execution (Rolland et al., 2007, Cowpe et al., 2009, Al-Kadhim et al., 2017).

In order to provide teaching and clinical training in endodontics, Malaysian undergraduate dental colleges must design and conduct programmes in accordance with the Malaysian Qualification agency (MQA), which set the minimum clinical experience (MCE) and expected clinical experience (ECE) of complete root canal treatment on 3 anterior teeth, 1 molar and passing one competency test. Students must also gain the competences required to execute endodontic treatment independently after graduation in order to acquire the requisite abilities.

The European Society of Endodontology has issued guidelines for undergraduate endodontics education in light of this. The European Society of Endodontology stated that the consistency and quality of a student's performance during preclinical and clinical years is more important than the overall number of clinical cases performed (De Moor et al., 2013). The quality of finished root canal procedures is the most important measure in evaluating a student's skill.

In addition, preclinical evaluations of students' root canal treatments will improve the quality of patient care in clinics (Ilgüy et al., 2013). However, it is widely believed that the total number of cases completed by students throughout their graduating years has a significant impact on general competency since it indicates their readiness to work independently on endodontic cases in the future (Chambers, 2012). Research into the quality and outcome of endodontic treatments has found a significant prevalence of poorly executed endodontic procedures performed by students (Lynch \& Bruke, 2006, Vukadinov et al., 2014). The complexity of the root canal system, a lack of understanding of treatment goals, and poor clinical skills could all be contributing factors.

For undergraduate dental students and general practitioners alike, endodontics can be one of the most challenging and stressful fields. This difficulty is thought to be due to the recent expansion in the field of endodontics in terms of clinical management of pulp and periapical diseases, as well as the complex anatomical diversity and large number of developed instruments and materials used in treatment, as well as a lack of self-confidence that makes many students feel unprepared to deal with endodontic treatment procedures (Tanalap et al., 2013). As all dental students complete their studies in the future, this degree of confidence is critical in assuring the quality of future general practitioners providing root canal therapy.

A recent study done by Almohaimede, 2018 have found a significant frequency of poorly performed RCTs with periradicular disease going unnoticed and untreated. This could be due to a variety of factors, including the difficulty of the technical procedures, a lack of understanding of the principles and goals of therapy, poor remuneration for the time spent, and insufficient undergraduate training (Almohaimede, 2018).

Davey et al. (2016) reported that the majority of dental students lack selfconfidence in performing root canal treatment, mainly due to the lack of clinical experience. In dentistry, it is required to repeat clinical procedures in order to develop clinical competence (Chambers, 
2012). It is not uncommon for recently graduated dentists to feel lacking in some clinical abilities, which is exacerbated by time constraints and practical opportunities in undergraduate courses. Keep in mind that this study looked at self-perceived confidence rather than competence (Murray \& Chandler, 1999). However, while competence is more important in dentistry, the importance of confidence in acquiring competence should not be overlooked (Honey et al., 2011). Therefore, teaching and number of practice in the clinic in undergraduate level can be very important to build confidence among students and ensuring the quality of root canal treatment procedure successfulness in the future.

The aim of this research is to study the perception final year students on their confidence level regarding root canal treatments from research based and nonresearch based public universities and their opinions on the quality of endodontic education.

\section{Materials and Methods}

\section{Study design}

A cross sectional study was conducted among Malaysian public university final year dental students' of 2020/2021 academic session who had performed at least one uncomplicated root canal treatment (with normal anatomy of pulp chamber and radicular pulp) throughout their clinical years. A questionnaire by Davey et al. (2014) was distributed among the students via Google form through their official university email. This study was conducted for 12 months starting from February 2020 until January 2021. An ethical approval was obtained from the Research Ethics Committee of Universiti Sains Islam Malaysia [USIM/REC/0720-129]. All participants agreed and consented for their participation in the study.

\section{Questionnaire}

Distributed questionnaires consist of 3 sections related to the student's general perception and confidence level in performing endodontic treatments, and their opinions on the learning process of the endodontic procedures. The first section was divided into two questions regarding their self-competence and self-confidence in performing endodontic treatments based on the type of tooth either single canal tooth or multirooted tooth. Second section was about students' perception on their level of confidence on endodontics performance based on the stages of the procedure as shown in Table 2 . The third section was about the students' opinion on the time spent and quality of endodontic education at their university. A Likert scale scoring of " 1 = Not confident at all" to "10 = Extremely confident" was employed with a cut-off point of 5 was later used to categorize the group of students into " $\geq 5=$ confidence" or " $<5=$ nonconfidence" for first and second section while " $\geq 5=$ adequate" and " $<5=$ inadequate" for analysis purposes.

\section{Statistical analysis}

Data were analysed using mean and standard deviation (SD), and frequency and percentage for descriptive analysis. Further analysis was performed using independent t-test for comparing mean between two groups on students' perception towards endodontic procedure. The significant level was set at $p<0.05$. Data analysis was performed using IBM SPSS Statistics for Windows, Version 26.0. Armonk, NY: IBM Corp.

\section{Results}

A total of 184 out of 235 final year dental students from all the public universities participated in the study (response rate 78\%). Table 1 showed the distribution of participants from different universities who participated in this study. The highest participation was Universiti Sains Malaysia $(87.0 \%)$ whilst the lowest was from Universiti Teknologi MARA (23.6\%).

Majority of the participants felt competent to perform an uncomplicated non-surgical endodontics treatment for single-rooted 
tooth (93.5\%) however, felt incompetent for multi-rooted tooth $(76.1 \%)$. On the other hand, majority of participant felt confident to perform uncomplicated non-surgical endodontics treatment on anterior and posterior tooth with a percentage of $97.3 \%$ and $75.5 \%$ respectively as shown in Table 2 .

Table 1. Distribution of final year students participated in the study $(n=184)$

$\begin{array}{llc}\text { University } & & \mathbf{N}(\%) \\ \text { Research based } & \text { University of Malaya } & 35 / 49(71.4) \\ & \text { Universiti Kebangsaan Malaysia } & 31 / 57(54.4) \\ & \text { Universiti Sains Malaysia } & 40 / 46(87.0) \\ \text { Non-research based } & \text { Universiti Teknologi MARA } & 21 / 89(23.6) \\ & \text { Universiti Sains Islam Malaysia } & 20 / 35(57.1) \\ & \text { International Islamic University of Malaysia } & 37 / 59(62.7)\end{array}$

Table 2. Students' perception on their level of competence and confidence in performing uncomplicated root canal treatment in clinical practice

$\begin{array}{llcc}\text { Type of tooth } & \text { Student's perception } & \mathbf{N} & \% \\ \text { Single-rooted } & \text { Competent } & 172 & 93.5 \\ & \text { Incompetent } & 12 & 6.5 \\ \text { Multi-rooted } & \text { Competent } & 44 & 23.9 \\ & \text { Incompetent } & 140 & 76.1 \\ \text { Anterior tooth } & \text { Confident } & 179 & 97.3 \\ & \text { Not confident } & 5 & 2.7 \\ \text { Posterior tooth } & \text { Confident } & 139 & 75.5 \\ & \text { Not confident } & 45 & 24.5\end{array}$

Descriptively, majority of the students had mean score of more than 5 which showed of perceived confident between university in performing every stage of root canal treatment. Most of the stages of RCT showed a significant difference of score between research and non-research-based university with $\mathrm{p}<0.05$. The detailed of the result with the p-value are shown in Table 3.
Majority of the participants responded that the amount of time spend on endodontics education, the quality of lecture and the quality of laboratory practical for endodontic session were adequate with the percentage of $97.8 \%, 98.9 \%$ and $91.8 \%$ respectively, as shown in Figure 1. 
Table 3. The comparison of mean score of student's perceptions in endodontics procedural stage

\begin{tabular}{|c|c|c|c|}
\hline \multirow[b]{2}{*}{ Endodontic procedural } & \multicolumn{2}{|c|}{ Type of university } & \multirow[b]{2}{*}{ p-value } \\
\hline & $\begin{array}{l}\text { Research } \\
\text { based } \\
\text { Mean (SD) }\end{array}$ & $\begin{array}{l}\text { Non-research } \\
\text { based } \\
\text { Mean (SD) }\end{array}$ & \\
\hline $\begin{array}{l}\text { - Determining restorability of a tooth which is } \\
\text { endodontically involved }\end{array}$ & $7.11(1.46)$ & $6.81(1.28)$ & .142 \\
\hline $\begin{array}{l}\text { - Knowing when to refer patients for more } \\
\text { complicated endodontic treatment that is } \\
\text { beyond your capabilities }\end{array}$ & $7.88(1.57)$ & $7.06(1.43)$ & .000 \\
\hline $\begin{array}{l}\text { - Providing analgesia to allow you to carry out } \\
\text { root canal treatment }\end{array}$ & $8.61(1.16)$ & $8.19(1.27)$ & .021 \\
\hline - Isolating the tooth & $8.59(1.17)$ & $8.13(1.19)$ & .009 \\
\hline - Preparing the access cavity & $7.60(1.20)$ & $7.46(1.21)$ & .430 \\
\hline $\begin{array}{l}\text { Determining working length of each canal using } \\
\text { an electronic apex locator and working length } \\
\text { radiograph }\end{array}$ & $7.51(1.33)$ & $7.08(1.31)$ & .030 \\
\hline $\begin{array}{l}\text { - Selecting appropriate irritant and irrigating the } \\
\text { root canal system }\end{array}$ & $8.17(1.24)$ & $7.56(1.34)$ & .002 \\
\hline - Cleaning and shaping root canal system & $7.55(1.45)$ & $6.99(1.44)$ & .010 \\
\hline - Placing an interappointment dressing & $8.22(1.37)$ & $7.47(1.42)$ & .000 \\
\hline - Filling root canal systems & $7.30(1.35)$ & $6.81(1.41)$ & .017 \\
\hline $\begin{array}{l}\text { - Understanding and appropriately managing the } \\
\text { risks associated with uncomplicated non- } \\
\text { surgical root canal treatment }\end{array}$ & $7.24(1.51)$ & $6.36(1.28)$ & .000 \\
\hline $\begin{array}{l}\text { - Taking pre-operative, intra-operative and post- } \\
\text { operative radiographs }\end{array}$ & $7.57(1.41)$ & $7.65(1.43)$ & .679 \\
\hline $\begin{array}{l}\text { Interpreting pre-operative, intra-operative and } \\
\text { post-operative radiographs }\end{array}$ & $8.09(1.27)$ & $7.53(1.15)$ & .002 \\
\hline $\begin{array}{l}\text { - Giving post-operative instructions to patients } \\
\text { following root canal treatment }\end{array}$ & $8.21(1.29)$ & $7.68(1.26)$ & .006 \\
\hline $\begin{array}{l}\text { - Assessing quality of a root filling post- } \\
\text { operatively }\end{array}$ & $7.98(1.35)$ & $7.36(1.20)$ & .001 \\
\hline - Determining correct recall period for the patient & $7.75(1.38)$ & $6.95(1.41)$ & .000 \\
\hline $\begin{array}{l}\text { - Knowing how to restore a tooth following root } \\
\text { canal treatment }\end{array}$ & $7.79(1.38)$ & $7.01(1.42)$ & .000 \\
\hline $\begin{array}{l}\text { - Knowing when a post is required to be placed in } \\
\text { a root canal to allow tooth restoration }\end{array}$ & $7.29(1.49)$ & $6.40(1.53)$ & .000 \\
\hline $\begin{array}{l}\text { Knowing how to place a post in a root canal and } \\
\text { using it to retain a restoration }\end{array}$ & $6.66(1.78)$ & $5.81(1.72)$ & .001 \\
\hline
\end{tabular}




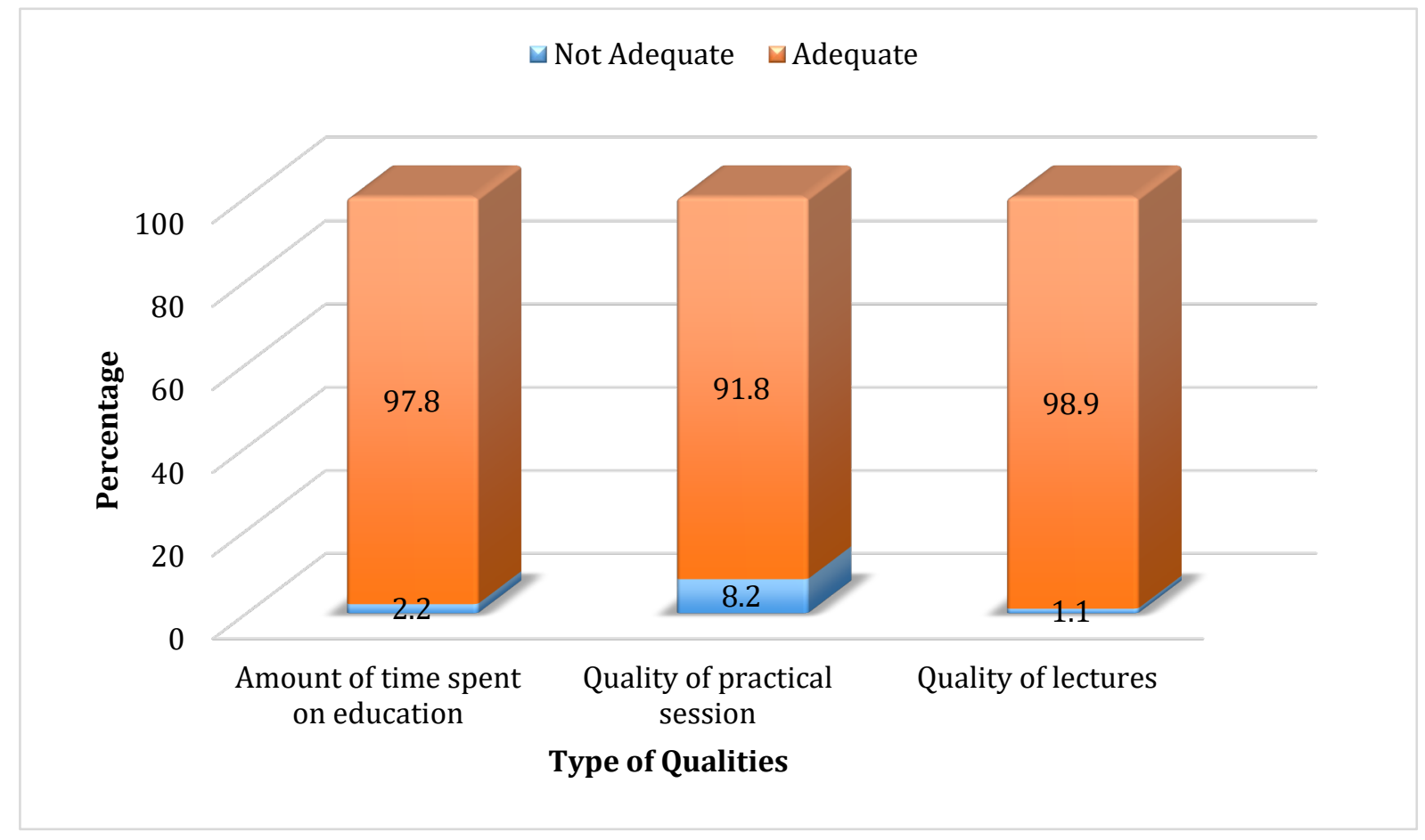

Figure 1. Students' opinion on the time spent and quality of endodontic education at their university

\section{Discussion}

The goal of this study was to explore more about final-year dental students' perceptions of root canal treatment confidence and competence, as well as their perceptions of the quality of endodontic education at their university and to compare between research based and non research based public university, the rational of dividing public universities to research based and non research based, as research based universities are well established and enjoying more senior and experienced academic members as compare to non research based universities.

The evaluation of students perception toward their competence is a vital step for the quality validation of graduating dental students. The competency-based curriculum recognizes essential components for dental practice and provides a sequence of defined learning outcomes that helps students to graduate as a qualified beginner. A recent study suggested that competency-based education may enhance the academic performance and metacognitive capability of students (Fan et al., 2015). The improved metacognition of students allows them to perform their self-assessment, which is of significant importance for practical clinical learning (Martinez, 2006). Therefore, it is imperative for students to gain insight into their cognitive processes and develop adequate skills for conducting self-evaluation of their respective competence and confidence levels. The current study is aimed to explore the undergraduate dental students' self-perceived confidence level while performing various stages of endodontic treatment.

Majority of the participants, around 93.5\% felt competent to do root canal treatment on single rooted tooth. The results of this study was higher than other study conduct in Saudi Arabia by (Alrahabi, 2017) which showed $78 \%$ of final year dental student were confident in performing root canal treatment on anterior teeth. 
However, the level of students confidence towards performing root canal treatment on multi-rooted tooth which only $23.9 \%$ of them who feel competent, These findings were consistent with the outcomes reported by (Alrahabi, 2017, Almohaimede, 2018, Ayhan et al., 2016). Most of the students felt not competent enough to perform root canal treatment on multi-rooted tooth regardless whether the students from research based or non research based universities.

Apart from that, as for performing root canal treatment based on the location of the tooth, $97.3 \%$ of the final year students feel confident when performing uncomplicated, non-surgical root canal treatment on anterior tooth.

A majority of participants $(97.8 \%)$ ranked the amount of time spent on endodontic education as adequate, our findings were higher as compared by other study done by (Puryer et al., 2016), who reported 72\% of students were satisfied with the time spent in endodontic education. Alrahabi, 2017 and Almohaimede, 2018 reported adequacy level of $87 \%$ and $83 \%$ respectively which are comparable to our study.

Moreover, the quality of lecture and the quality of preclinical practical for endodontic session were adequate with the percentage of $98.9 \%$ and $91.8 \%$ respectively, these findings were comparable but higher with other studies (Javed et al., 2021, Puryer et al., 2016) who reported adequacy level of $78 \%$ and $75 \%$ respectively.

Nevertheless, according to the perception of confidence of the respondents related to every stage of non-surgical root canal treatment, briefly starting from how to determine the restorability of the tooth until knowing how to restore following the treatment, can be concluded that most of the final year dental students were confident in performing every stage of the root canal treatment even-though there was a significant difference $(\mathrm{P}<0.05)$ in confidence level between the two main groups which are research based and non-research based university. However, there was only a slight mean difference in the overall comparison. From here, it shows that the students have acknowledge the theory and practical clinically very well but somehow due to certain circumstances, final year dental students lacked of clinical sessions to practice as much as they could. This can be proven through their answers to the last two open questions in the survey, most of students have highlighted a few factors that might influence their confidence level. The responses stated that, due to the outbreak of pandemic Covid-19 around the globe, preclinical and clinical sessions were reduced and they were given limited of time to complete all the required procedures. In addition, the availability of patient that indicated for endodontic treatment especially molar cases were low and difficult to obtain and had been worse in the current pandemic situation.

A lack of clinical experience in the undergraduate curriculum, according to (Murray et al., 1999), diminishes the confidence that emerges with clinical practise. Furthermore, an overly crowded curriculum will undermine self-confidence. Therefore, most of the suggestions on how to improve and overcome these factors, majority of responses suggested to increase the number of practical sessions of endodontic treatment and do regular discussion upon any cases related to root canal treatment procedures. It can be seen here that, most of the final year students seemed to have a great concern toward the clinical care education.

It's important to remember that a student's high level of confidence in a technique doesn't guarantee that they'll be able to execute it successfully. Although students may possess the necessary skills, their context and internal judgement of their abilities may not give them with the selfbelief (confidence) to perform the surgery. Overconfident students may endanger patients by performing treatments above their skill level (Gilmour et al., 2017). More clinical experience is likely to boost confidence and competence, especially if the clinical experience is structured (Choudhry et al., 2005). Although gaining more RCT 
clinical experience does not ensure competence, it is vital that undergraduate students obtain appropriate clinical exposure to endodontic treatments; otherwise, they are unlikely to achieve competence or confidence (Youngson et al., 2007). However, improving student experience is not always straightforward, as constraints like as a shortage of suitable case for undergraduate level (Gilmour et al., 2017). Students must develop comprehension and an accurate selfassessment of their own proficiency levels and associated confidence, regardless of their prior experience, so that, if necessary, additional training and clinical experience can be obtained after graduation. After convocation, Dental officers must be able to use portfolios, reflection, and plans for personal development to address their 'weak' areas through training (Gilmour et al., 2017).

\section{Limitation and Recommendation}

\section{Limitation}

Participant feedback was low, and the reason behind that was due to communicating with other universities was via online platform (WhatsApp Messenger). There were no Physical meetings due to current pandemic (Covid-19 outbreak) situation. Therefore, if there is any problems or inquiries, we had difficulties to attend with the problems. We were only depended on each of the representatives from the involved universities to spread the questionnaires and ask their batchmates to answer all the questionnaires.

\section{Recommendation}

As for the recommendation, we suggest to expand the number of samples which can include the private dental schools in the study so that comparison of confidence level among dental students in public and private universities can be made and also their quality of education in each of the universities. Moreover to enhance participant feedback, a face to face communication with other universities students to clarify the research objectives should be implemented. Further investigation on how different teaching methods, time spent teaching or the mount of clinical experience has an effect on student confidence

\section{Conclusion}

Perception of confidence and competence when performing uncomplicated root canal treatment were not obviously different between universities. However, many participants did not feel confident and competent, at some circumstances, indicating that there is scope to enhance endodontic education at their respective universities. Participants suggested that more different teaching techniques be included, as well as an increase in the number of preclinical and clinical sessions, and self-assessment.

\section{Acknowledgement}

The authors are most grateful to the Faculty of Dentistry, USIM, UM, UiTM, UKM, USM, UIA for the approval and support to conduct this study.

\section{Conflict of Interest}

The authors declare that they have no financial or other conflicts of interest in relation to this research and its publication.

\section{References}

Al-Kadhim, A.H., Rajion, Z.A., Malik, N.A., Jaafar, A. (2017). Morphology of maxillary first molar analyzed by cone-beam computed tomography among Malaysian: Variations in the number of roots and canals and the incidence of fusion. IIUM Medical Journal Malaysia, 16(2), 33-39.

Almohaimede, A.A. (2018). Clinical undergraduate endodontic teaching in King Saud University: Student's experience, perception, and self-confidence levels. International Journal of Dental and Oral Health, 4(1),1-5.

Alrahabi, M. (2017). The Confidence of Undergraduate Dental Students in Saudi Arabia in Performing Endodontic Treatment. European Journal of Dentistry, 11(1), 217-221.

Awooda, E.M., Mudathir, M.S., Mahmoud, S.A. (2014). Confidence level in performing endodontic treatment among final year undergraduate dental students from the University of Medical Science 
and Technology, Sudan Saudi Endodontic Journal, 6, 26-30.

Ayhan, T., Barut, G., Tanalp, J. (2016). The self-confidence levels of senior dental students during endodontic treatment procedures. Turkey Endodontic Journal, 1,19-22.

Brennan, D.S., Spencer, A.J. (2003). Service provision trends among Australian private general dental practitioners: $1983 / 84$ to $1998 / 99$. International Dental Journal, 53,145-152.

Chambers, D. (2012). Learning Curves: What Do Dental Students Learn from Repeated Practice of Clinical Procedures? Journal of Dental education, 76(3), 291-302.

Choudhry, N.K., Fletcher, R.H., Soumerai, S.B. (2005). Systematic review: The relationship between clinical experience and quality of health care. Annual of Internal Medicine, 142, 260-273.

Cowpe, J., Plasschaert, A., Harzer, W., Vinkka-Puhakka, H., Walmsley, A.D. (2010). Profile and competences for the graduating European dentist - update 2009. European Journal of Dental Education, 14, 193-202.

Davey, J., Bryant, S.T., Dummer, P.M.H. (2015). The confidence of undergraduate dental students when performing root canal treatment and their perception of the quality of endodontic education. European Journal of Dental Education, 19, 229-234.

De Moor, R., Hulsmann, M., Kirkevang, L.L., Tanalp, J., Whitworth, J. (2013). European Society of Endodontology. Undergraduate curriculum guidelines for endodontology. International Endodontic Journal, 46,1105-1114.

European Society of Endodontology. (2006). Quality guidelines for endodontic treatment: Consensus report of the European Society of Endodontology. International Endodontic Journal, 39, 921-930.

Fan, J.Y., Wang, Y.H., Chao, L.F., Jane, S.W., Hsu, L.L. (2015). Performance evaluation of nursing students following competency-based education. Nurse Education Today, 35, 97-103.

Gilmour, A.S.M., Welply, A., Cowpe, J.G., Bullock, A.D., Jones, R.J. (2016). The undergraduate preparation of dentists: Confidence levels of final year dental students at the School of Dentistry in Cardiff. British Dental Journal, 221, 349-354.

Honey, J., Lynch, D.C., Bruke, F.M., Gilmour, A.S. (2011). Ready for practice? A study of confidence levels of final year dental students at Cardiff University and University College Cork. European Journal of Dental Education, 15(2), 93-103.

Ilgüy, D., Ilgüy, M., Fisekçioglu, E., Ersan, N., Tanalp, J., Dölekoglu, S. (2013). Assessment of root canal treatment outcomes performed by Turkish dental students: Results after two years. Journal of Dental Education, 77, 502-509.

Javed, M.Q., Khan, A.M., Bhatti, U.A. (2021). Evaluation of undergraduate dental students self-perceived confidence level regarding endodontic procedures: A questionnaire survey. Saudi Endodontic Journal, 11, 228-234.

Lynch, C.D., Burke, F.M. (2006). Quality of root canal fillings performed by undergraduate dental students on single-rooted teeth. European Journal of Dental Education, 10, 67-72.

Martinez, M.M. (2006). What is metacognition? Phi Delta Kappan, 87, 696-699.
Murray, C.M., Chandler, N.P. (2014). Undergraduate endodontic teaching in New Zealand: Students' experience, perceptions and self- confidence levels. Australian Endodontic Journal, 40(3), 116-122.

Murray, F.J., Blinkhorn, A.S., Bulman, J. (1999). An assessment of the views held by recent graduates on their undergraduate course. European Journal of Dental Education, 3, 3-9.

Puryer, J., Amin, S., Turner, M. (2016). Undergraduate confidence when undertaking root canal treatment and their perception of the quality of their endodontic education. Dentistry Journal (Basel), 5, 1-10.

Rolland, S., Hobson, R., Hanwell, S. (2007). Clinical competency exercises: Some student perceptions. European Journal of Dental Education, 11,184-191.

Seijo, M.O., Ferreira, E.F., Ribeiro Sobrinho, A.P., Paiva, S.M., Martins, R.C. (2013). Learning experience in endodontics: Brazilian students' perceptions. Journal of Dental Education, 77, 648-655.

Skudutyte-Rysstad, R., Eriksen, H.M. (2006). Endodontic status amongst 35-year-old 0slo citizens and changes over a 30-year period. International Endodontic Journal, 39, 637-642.

Tanalap, J., Guven, E., Oktay, I. (2013). Evaluation of dental students' perception and self-confidence levels regarding endodontic treatment. European Journal of Dentistry, 7(2), 218-224.

Vukadinov, T., Blažić, L., Kantardžić, I., Lainović, T. (2014). Technical quality of root fillings performed by undergraduate students: A radiographic study. Scientific World Journal, 1-6.

Youngson, C.C., Molyneux, L.E., Fox, K., Boyle, E.L., Preston, A.J. (2007). Undergraduate requirements in restorative dentistry in the UK and Ireland. British Dental Journal, 203 (Suppl. 5), 9-14. 